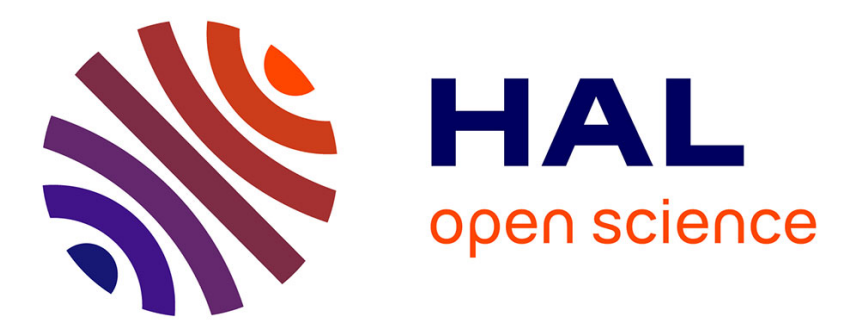

\title{
Life cycle assessment of industrial symbiosis: A critical review of relevant reference scenarios
}

\author{
Lynda Aissani, Antoine Lacassagne, Jean-Baptiste Bahers, Samuel Le Feon
}

\section{To cite this version:}

Lynda Aissani, Antoine Lacassagne, Jean-Baptiste Bahers, Samuel Le Feon. Life cycle assessment of industrial symbiosis: A critical review of relevant reference scenarios. Journal of Industrial Ecology, 2019, 23 (4), pp.972-985. 10.1111/jiec.12842 . halshs-02058745

\section{HAL Id: halshs-02058745 \\ https://shs.hal.science/halshs-02058745}

Submitted on 20 Mar 2019

HAL is a multi-disciplinary open access archive for the deposit and dissemination of scientific research documents, whether they are published or not. The documents may come from teaching and research institutions in France or abroad, or from public or private research centers.
L'archive ouverte pluridisciplinaire HAL, est destinée au dépôt et à la diffusion de documents scientifiques de niveau recherche, publiés ou non, émanant des établissements d'enseignement et de recherche français ou étrangers, des laboratoires publics ou privés. 


\title{
Life cycle assessment of industrial symbiosis
}

\section{A critical review of relevant reference scenarios}

\author{
Lynda Aissani $^{\mathrm{ab}}$, Antoine Lacassagne ${ }^{\mathrm{ab}}$, Jean-Baptiste Bahers ${ }^{\mathrm{c}, \mathrm{d}}$, Samuel Le Féon ${ }^{\mathrm{ab}}$

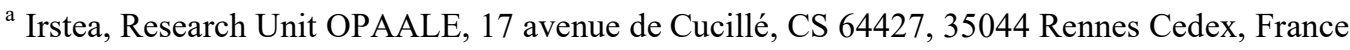 \\ ${ }^{\mathrm{b}}$ Université Bretagne Loire, France \\ ${ }^{\mathrm{c}}$ Ecole des Métiers de l’Environnement, Avenue Robert Schuman, 35170 Bruz, France \\ ${ }^{\mathrm{d}}$ University of Rennes 2, CNRS UMR 6590 ESO-Rennes, Place Recteur Henri le Moal, 35000 Rennes, France \\ *Corresponding author: telephone: (+33) 223482 147, fax: (+33) 223482 115, lynda.aissani@irstea.fr
}

Keywords: Industrial ecology, sensitivity analysis, scenario analysis, allocation, environmental assessment, territory

\footnotetext{
Summary

This paper highlights the methods and parameters used to define and design a reference scenario to be compared with an industrial symbiosis scenario using the Life Cycle Assessment (LCA) methodology. To this end, a critical review was conducted of 21 peer-reviewed papers using LCA in the field of industrial symbiosis. The analysis focuses on the definition and design of reference scenarios thr ough five cross-analyses to determine correlations between the type and the number of reference scenarios and the type of industrial symbiosis scenarios studied and also some LCA characteristics such as the functional unit, the type of data used and the use of sensitivity analysis. Results show that the definition of reference scenarios depends mainly on the type of industrial symbiosis scenario considered. For a current industrial symbiosis developed at an industrial scale, the suitable reference scenario is mainly a hypothetical non-symbiotic reference scenario. For a prospective industrial symbiosis, the suitable reference scenario is mainly a current non -symbiotic reference scenario. Thanks to this critical review, the problem of variability of reference scenarios emerges. To resolve it, the authors analyze different reference scenarios or use of sensitivity analysis. What is more, territorial aspects are rarely taken into account in the design of reference scenarios. It is clearly a gap for LCA of indust rial symbiosis because of their territorial influence. The new research challenge is to include the consideration of territorial aspects to define and design the worst and best cases reference scenario to assess strict environmental performances of industrial symbiosis.
}

\section{INTRODUCTION}

Industrial symbiosis (IS) can be described as by-product exchange and organizational interactions between companies such as recycling of byproducts, sharing of services, and knowledge (Chertow, 2000). IS is composed of industrial synergies involving "industries that realize a beneficial conversion of their by-products and wastes into resources"; that is, that wastes are fully recycled within the industrial system concerned (Ehrenfeld \& Gertler, 1997). The analogy to the concept of biological symbiosis is central to IS. In biology, symbiosis describes any close relationships between two species. Under such circumstances, either one or both species cannot survive without the other. The application of the concept of symbiosis in industrial systems "involve[es] the creation of linkages between firms to raise the efficiency, measured at the scale of the system as a whole, of material and energy flows through the entire cluster of processes" (Chapman \& Reiss, 1998) and depends on available raw materials (Côté \& Cohen-Rosenthal, 1998).

The system composed of IS presents strong linkages because of the vital need for each entity to manage the symbiosis in all circumstances by "establishing close working agreements between normally unrelated companies" (Jensen, Bassona, Hellawell, Bailey, \& Leacha, 2011). "Working agreement" is one key to IS development to allow the sharing of benefits and the mutual management of systemic constraints. Collaboration and synergistic possibilities offered by geographic proximity are other keys to IS (Chertow, 2000), which eases the building of trust and cooperation (Jensen et al., 2011). Without these two features, the level of knowledge exchange required to facilitate IS is both difficult and costly to obtain (Christiansen 1994 cited in Ehrenfeld \& Gertler, 1997). As IS aims at reducing the environmental impact of industrial systems, the environmental benefits of different case studies have often been quantified (Chertow \& Lombardi, 2005; Jacobsen, 2006) by comparing the IS with stand-alone 
plants to quantify the raw materials not used and pollutant not released to the environment in the IS case.

However, these calculations are presented without accounting for assumptions or explaining the method of calculation (Wolf \& Karlsson, 2008) and some authors highlight the need of a relevant metric to quantify benefits of IS (Trokanas, Cecelja, \& Raafat, 2015). Thenceforth, a specific method is needed to manage assumptions and to turn calculations of material flows into calculation of the environmental impact.

Life cycle assessment (LCA) is a standardized methodology used to address the potential environmental impacts throughout a life cycle extending from raw material extraction through production, use, end-of-life treatment, recycling, and final disposal (ISO, 2006a). The LCA methodology comprises four steps: goal and scope definition, inventory analysis, impact assessment, and the interpretation of the results (ISO, 2006a). LCA has already been successfully applied to systems such as IS (Singh, Lou, Yaws, Hopper, \& Pike, 2007).

However, using LCA to study the environmental impacts of IS presents specific issues. Mattila, Lehtoranta, Sokka, Melanen, and Nissinen (2012) classified IS research in five thematic groups: the quantification of environmental impacts of an IS (analysis), the optimization of the system (improvement), the definition of the boundaries of the studied system (expansion), the environmental assessment of a designed symbiosis (ecoindustrial parks), and the assessment of wider circular systems (circular economy). The quantification of environmental benefits is a major question related to four of the groups in this classification: analysis, improvement, design of eco-industrial parks, and circular economy, depending on the aim of the LCA. The quantification of environmental benefits of a product or a system like IS should be done by comparing it to another system that at least performs the same function (ISO, 2006b). This function is identified by the author of the LCA and quantified into a functional unit to ensure the comparability of LCA results (ISO, 2006b). This functional unit provides a basis to compare the IS with the reference and alternative scenarios. A reference scenario is often chosen to be compared to the studied scenario. Indeed, environmental performance of the studied scenario is represented by the mathematical differences in the environmental impact scores between the studied scenario and the reference scenario. The reference scenarios, as well as scenarios with improvements (called alternative scenarios), are designed to produce the same function as the studied scenario (Martin, Svensson,\& Eklund, 2015). The specific recirculation of materials in IS makes the design of the alternative scenarios sensitive to the methodological choices made by the LCA practitioner: which raw material should be considered instead of the recycled by-products of the symbiosis? How should the by-product be managed if it is not recycled? The selection of the correct reference scenario(s) reduces the risk of overestimating or underestimating the environmental performance of by-product exchanges (Mattila et al., 2012). The definition and the design of the reference scenario are consequently essential issues for the best assessment of the environmental performances of the studied scenario. However, this type of issue is not identified as being highly significant in LCA standards (ISO14040 2006, ISO14044 2006, European Commission, 2010). Some literature reviews concerning LCA of IS exist but most of them focus on the improvement of IS according to, for example, a multiobjective approach (Boix, Montastruc, Azzaro-Pantel, \& Domenech, 2015), the optimization of the network structure (Kastner, Lau, \& Kraft, 2015), or the social-material Network Analyses (Schiller, Penn, \& Basson, 2014). These papers highlight the importance of environmental assessment for the IS case studies but rarely question the reliability of the comparison, which is often based on a reference scenario that is not especially ambitious such stand-alone plant. Even though such an improvement is essential, the strictly environmental relevance of IS must be shown as compared to a reference situation depending on whether a business-as-usual scenario or an alternative scenario is used. The scientific literature about the environmental assessment of IS case studies grows and a few original papers provide some guidance regarding the definition and design of a reference scenario but not methodological framework. Indeed, Martin et al. (2015) point out generally the variability of methodological choices to perform LCA of IS case studies due to "the absence of agreed rules, methods, and indicators." They explain that "the reference scenarios created are only a speculative representation of what would have happened if the exchanges had not taken place. Based on an available understanding of the current system, metabolism of products from the system and regional data are used to construct reference scenarios." For Martin et al. (2015), the building of reference scenario(s) is a specific and important methodological step to quantify environmental benefits of IS. They describe some overly general guidelines to define and design the reference scenario(s) based on some previous work (Sokka, 2011). Mattila et al. (2012) propose an overview of methodological aspects of LCA of IS case studies. They point out the issue of the building of reference scenario and focus on the usefulness of environmentally extended input-output to overcome the multifunctionality issue for the definition and design of the reference scenario. According to these authors, the use of the hybrid input-output LCA methods allows a suitable definition of reference scenario. However, this approach "freezes" the reference scenario according to the economic data and does not take into account scenario involving marginal changes.

Therefore, this present review does not focus on the improvement of IS scenario as in most papers. Its aim is to provide an overview of how LCA practitioners manage these methodological issues when building reference scenarios comparable with the system under study and how they improve this methodological step. The paper is structured in three main sections. The first describes the method used to select scientific articles and provides definitions for essential terms. Section 2 describes different cross-analyses of peer-reviewed papers to better understand recurrences and to identify gaps in the literature. Finally, Section 4 tackles the main guidelines to define and design a reference scenario for LCA of IS.

\section{METHODS}

This section first defines the corpus that consists of a selection of papers applying LCA to IS. Once the corpus has been defined, it is put in the scientific context of industrial ecology due to a network analysis. Some terms are defined to enable the identification of two typologies concerning the scenarios studied and the reference scenario. Finally, the methodology behind the critical analysis is described. 
F I G U R E Flow chart describing the paper collection approach

\section{I Corpus definition and description}

\subsection{Corpus definition}

Two databases were consulted in 2018 to identify an exhaustive corpus of scientific articles considering at least one reference scenario to perform the LCA of IS: Scopus and Web of science. The search equation used on scopus.com was: TITLE-ABS-KEY (( LCA » OR « life cycle assessment » OR « environmental assessment ») AND (« eco industrial park» OR « industrial symbiosis »)) AND (EXCLUDE (PUBYEAR, 2018)). The search equation used on web of science was: TS = ((« industrial symbiosis » OR « eco-industrial park ») AND (« life cycle assessment » OR LCA OR « environmental assessment »)) AND [excluding] PUBLICATION YEARS: (2018). A total of 142 papers were found in these searches, not counting duplications (available in the Supporting Information). The first inspection of the 142 papers aimed at selecting 25 of them that used LCA to assess an IS. Another paper was added to this corpus (Figure 1).

All the papers in the corpus were published less than a decade ago (Table 1).Indeed, the first case study of an IS that described the famous industrial ecosystem of Kalundborg, in Denmark, was published only 20 years ago (Ehrenfeld \& Gertler, 1997). In the first decade, research works on industrial symbioses focused on characterizing their network and their metabolism, using tools like material flow analysis (MFA). There was an underlying consensus in many studies that IS should result in environmental benefits (Martin, 2013), explaining why the quantification of their environmental impacts using LCA was studied later. LCA is a relatively new methodology in IS context and was originally used to assess the environmental impacts of products. Its use for other topics is quite recent and responds to the needs expressed by field experts. Year 2015 was the first most productive year with five published case studies, a few years after the first methodological works on LCA of industrial symbioses (Mattila et al., 2012; Sokka, 2011; Van Berkel, 2010). The other year that saw several publications was 2011, with four papers.

Out of the 26 case studies, 12 were written in Europe, of which seven in Sweden and Finland. This is logical given the number of methodological papers published in these two countries to improve the quality of LCA studies on IS (Martin, 2013; Mattila et al., 2012; Sokka, 2011). Moreover, the first IS was developed close by, in Kalundborg, Denmark, showing that Scandinavia is a leader in IS studies. Six case studies were conducted in East Asia (China, South-Korea, Taiwan, and Japan) in a context of rapid economic growth and a high population density that encouraged prevention of overpollution in industrial areas through the use of industrial ecology solutions. Two papers were described in case studies in the United States and one in Australia. The most frequently studied area was the eco-town of Kawasaki, in Japan, a district of an urban area containing industrial symbioses. This case was the subject of three of the papers in the corpus.

\subsubsection{Definition of terms and typologies}

To avoid any ambiguity between "definition" and "design," and "studied scenario" and "reference scenario," these terms have to be precisely defined. Concerning the reference and the studied scenario, a typology was proposed.

\section{Definition of terms}

In the rest of the paper, a distinction is made between the studied and reference scenario. A studied scenario refers to the object under study, which is always an IS in this paper. The environmental performances of the studied scenario can be compared with the environmental performances of alternative and reference scenarios. An alternative scenario is a version of the scenario under study which presents some differences (in data or in the process) to check the environmental relevance of the studied scenario. A reference scenario is needed to put the environmental performances of the studied scenario into perspective according to the situation being used as a basis for the comparison. Two terms are used to characterize the building of a reference scenario. The term "definition" describes the nature of the reference scenario, whereas the term "design" describes the way it is modeled (the data used, the processes included, etc.). As different types of studied scenario and reference scenarios were encountered in the review, two typologies are proposed in the two following sections.

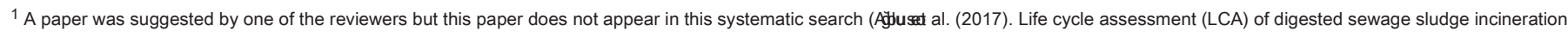
for heat and power production. Journal of Cleaner Production, 142, 1684-1692.).
} 
TA B L E 1 References of the papers composing the corpus

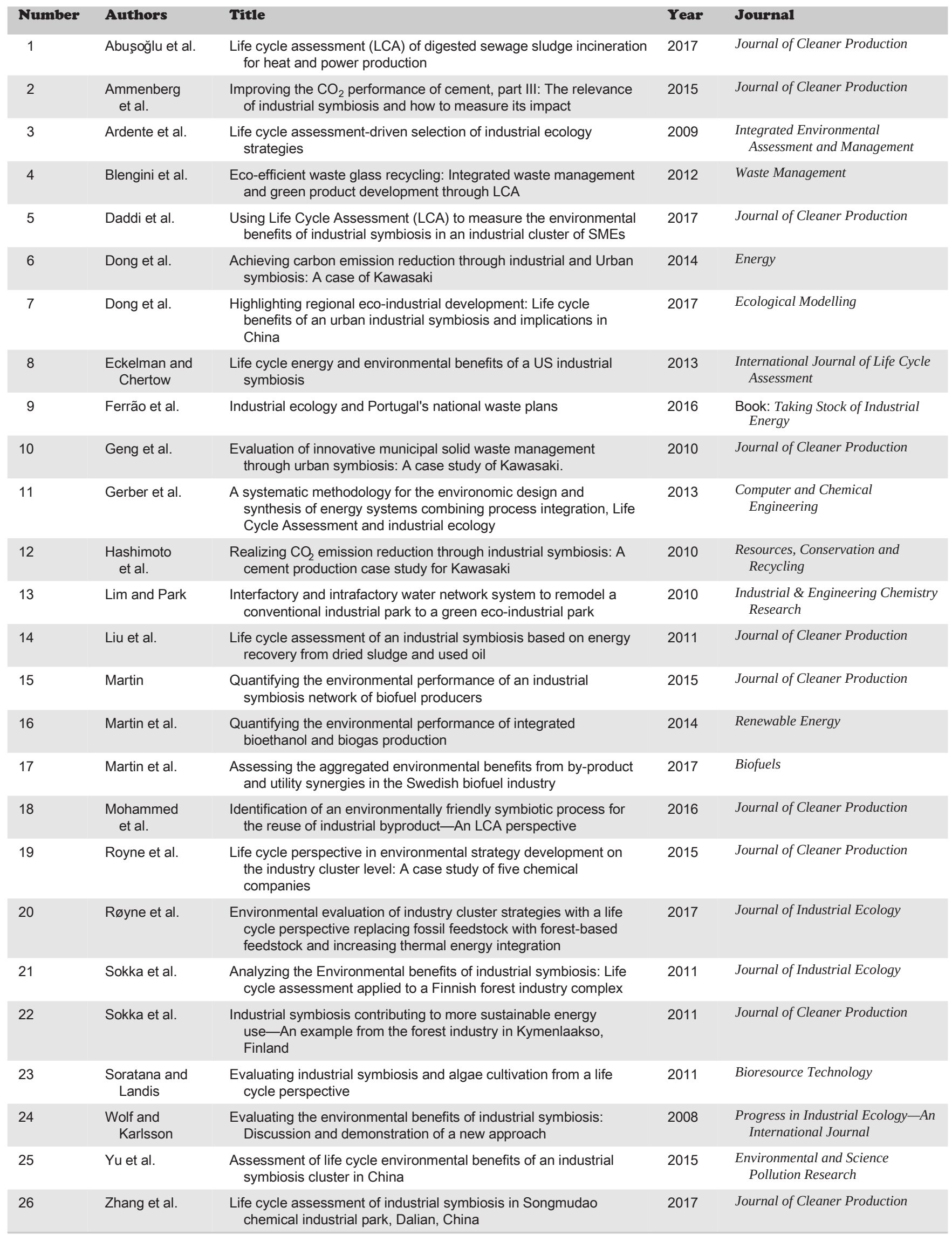




\section{Typology of studied scenarios}

It is important to find a typology of the studied scenario to highlight potential correlations with the definition and the design of the reference scenarios. Three types of studied scenarios can be identified in the corpus:

- Current IS: The studied scenario is an existing IS developed at an industrial scale, with material and organizational linkages between the different companies constituting the symbiosis.

- Prospective IS: The studied scenario is a prospective IS that does not exist. It is composed of the linkages between current companies and of a new process added to link companies or the implementation of a whole IS in a given area.

- Optimized IS: The studied scenario is based on existing IS with the addition of new linkages or of new processes to recycle more flows into the existing symbiosis.

In this corpus comprising 26 papers, 12 papers study current symbiosis scenario, 11 study prospective symbiosis scenario, and three study an optimized scenario.

\section{Typology of reference scenarios}

Four types of reference scenarios were encountered in the present corpus:

- A current nonsymbiotic reference scenario (CNSRS): It represents current industrial processes with no symbiotic exchanges between the companies concerned (a business-as-usual scenario). This type of reference scenario was encountered in 11 papers.

- A hypothetical nonsymbiotic reference scenario (HNSRS): The reference scenario is built with no symbiotic exchanges between the companies concerned. It does not represent current industrial processes but a hypothetical scenario that is an alternative to the business-as-usual scenario. This type of reference scenario was encountered in 11 papers.

- A current symbiotic reference scenario (CSRS): The reference scenario is built with symbiotic exchanges between the companies concerned. It represents current industrial processes. This type of reference scenario was encountered in three papers.

- A hypothetical symbiotic reference scenario (HSRS): The reference scenario is built with symbiotic exchanges between the companies concerned. This reference scenario does not represent current industrial processes but a hypothetic scenario that is an alternative to the current IS. This type of reference scenario was encountered in one paper.

The nonsymbiotic reference scenario was encountered in 22 out of the 26 papers, whereas symbiotic reference scenario was encountered in only four out of the 26 papers. It should be noted that just one case study used two types of reference scenarios.

\section{Consideration of territorial aspects}

Industrial symbioses take place in a regional context with different spatial, economic, and social characteristics (Lowe \& Evans, 1995). These characteristics refer to the territorial aspects. These territorial aspects could strongly influence the development and the design of industrial symbioses (Cohen-Rosenthal, 2004). Indeed, local stakeholders can take decisions according to these social, economic, and spatial characteristics (Kastner et al., 2015; Schiller et al., 2014). These decisions could lead to the development of IS for a specific location or to the improvement/evolution of a nonsymbiotic situation. So, the studied scenarios and reference scenarios should be defined and designed in LCA with the consideration of these territorial aspects (Loiseau et al., 2018). This is obvious but, in reality, it is really difficult to take into account territorial aspects because of lack of methodology and data. Sometimes, some authors propose a quite rough territorial aspect consideration for lack of anything better.

\section{2 | Methodology behind the critical review analysis}

In order to identify the best practices to define and design the reference scenario, it is advisable to conduct a cross-analysis to identify relevant correlations between some LCA characteristics (Table 2) and the type of reference scenario.

Six characteristics were assumed to be relevant for the definition and design of reference scenarios and broken down into modalities:

- Type of functional unit:

- One-dimensional—when it describes only one function; or multidimensional—when it describes several functions.

- Based on output, as is the case for LCAs of products; or based on input, as is the case for LCAs of waste treatment.

- Number of reference scenarios.

- Type of data: site-specific, average, or marginal.

- Use of sensitivity analysis: yes or no. 
TA B L E 2 Summary of the LCA characteristics of the peer-reviewed papers

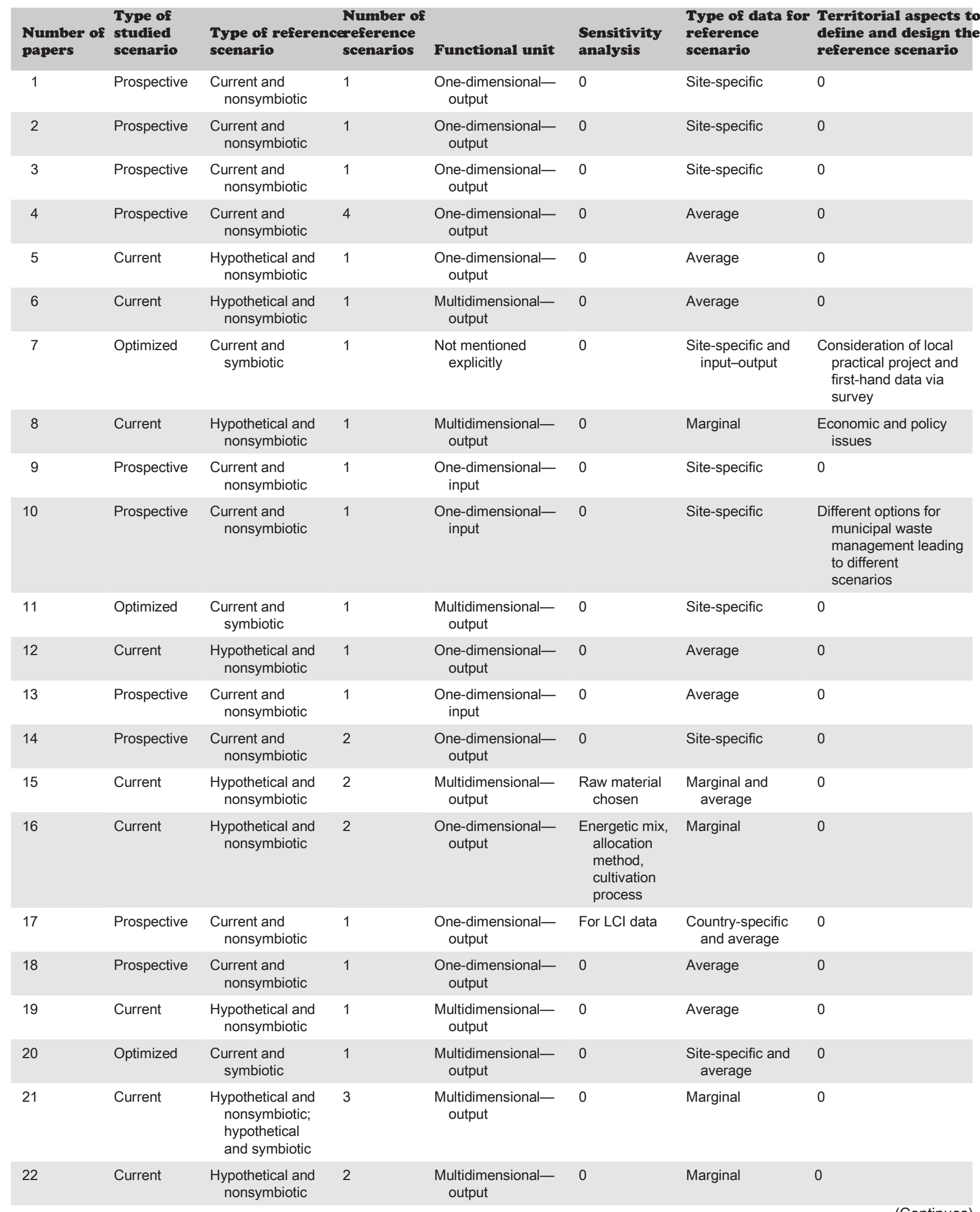

(Continues) 
TA B L E 2 (Continued)

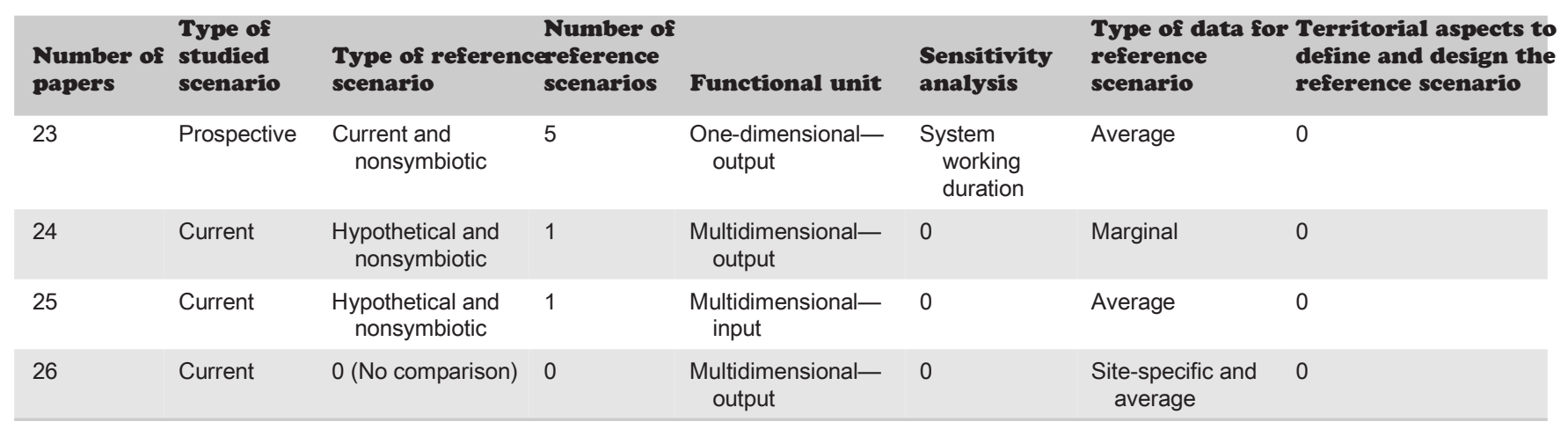

- Consideration of territorial aspects: yes or no.

Thus, five analyses were performed:

- The first one consists of crossing the typology of the reference scenario and the typology of the studied scenario to see whether the definition of the reference scenario depends on the type of studied scenarios (type of symbiosis).

- The second analysis consists of crossing the typology of the functional unit and the typology of the reference scenario to see whether the design of the reference scenario depends on the type of functional unit (one-dimensional or multidimensional, input or output type) and how the number or reference flows could describe the complexity of the studied systems.

- The third analysis consists of crossing the number of reference scenarios and the type of studied scenario with the type of reference scenario to see whether many reference scenarios are required according to the types of reference scenario and studied scenario.

- The fourth analysis consists of crossing the use of sensitivity analysis and the type of reference scenario to see whether LCA practitioners consider the reference scenarios as sensitive.

- The fifth analysis consists of crossing the number of industries/companies and the number of exchanged flows for the studied system to understand how the level of IS could explain the sensitivity issue.

- The sixth analysis consists of crossing the type of data (site-specific, local, or marginal) and the type of reference scenarios to see whether the choice of a type of reference scenario involves the use of a precise type of data.

\section{RESULTS OF THE CROSS-ANALYSES}

Six cross-analyses were conducted to identify the main parameters that are useful to build the reference scenario. Results of these six crossanalyses that intersect the type of reference scenario with the type of functional unit, the number of reference scenarios, the use of sensitivity analysis, the numbers of industries and exchanged flows, and the type of data are presented in this section. In addition, the mention of territorial aspects in reference scenario design is discussed. Because of the small size of the corpus, it is risky to generalize the results of the different cross-analyses but they can highlight some promising aspects to discuss the question of the definition and the design of reference scenarios.

\subsection{Cross-analysis between the reference scenario and the studied scenario}

To see whether the definition of the reference scenario depends on the type of studied scenarios, a simple cross-analysis was conducted to refine the description of the corpus (Table 3).

First of all, in prospective symbiosis case studies, the authors use a CNSRS (11 out of 11) for the comparison. The other types of reference scenarios were not encountered in the prospective symbiosis case studies, whereas it is possible to use an HNSRS or an HSRS for comparison with the prospective symbiosis. The authors of current symbiosis case studies preferentially build an HNSRS (11 out of 11). One of the current symbiosis case studies has both an HNSRS and an HSRS.he optimized symbiosis case studies were compared with CSRS (three out of three). Three expected correlations between the type of studied scenarios and the type of reference scenario used can be identified to summarize these corpus characteristics:

- CNSRS was always built for comparison with prospective symbiosis scenarios.

- HNSRS was always built for comparison with current symbiosis scenarios.

- CSRS was built for comparison with optimized symbiosis. 
Types of reference scenarios according to the types of studied scenarios

\begin{tabular}{|c|c|c|c|c|c|}
\hline & & \multicolumn{4}{|c|}{ Types of studied scenarios } \\
\hline & & Prospective symbiosis & Current symbiosis & Optimized symbiosis & Total \\
\hline \multirow[t]{3}{*}{ Types of reference scenarios } & Number of HNSRS & 0 & 11 & 0 & 11 \\
\hline & Number of CSRS & 0 & 0 & 3 & 3 \\
\hline & Number of HSRS & 0 & 1 & 0 & 0 \\
\hline
\end{tabular}

Note. In this study, an HNSRS was also used. To avoid double counting, this was not taken into account in the total. HNSR \&pothetical nonsymbiotic reference scenario; CNSRS current nonsymbiotic reference scenario; CRSRS= current symbiotic reference scenario; HSRS= hypothetical symbiotic reference scenario.

TA B L E 4 Type of functional unit according to the type of reference scenario

\begin{tabular}{|c|c|c|c|c|c|c|c|c|}
\hline \multicolumn{9}{|c|}{ Type of functional unit } \\
\hline & & Input & Output & Total & One-dimensiona & aMultidimension & aTotal & Not mentioned explicitly \\
\hline \multirow[t]{6}{*}{ Type of reference scenario } & HNSRS & 1 & 10 & 11 & 4 & 7 & 11 & 0 \\
\hline & CNSRS & 4 & 7 & 11 & 10 & 1 & 11 & 0 \\
\hline & CSRS & 0 & 2 & 2 & 0 & 2 & 2 & 1 \\
\hline & HSRS & 0 & 1 & 1 & 0 & 1 & 0 & 0 \\
\hline & No reference scenario & 0 & 1 & 0 & 0 & 1 & 1 & 0 \\
\hline & Total & 5 & 20 & 25 & 14 & 11 & 25 & 1 \\
\hline
\end{tabular}

Note. In this study, an HNSRS was also used. To avoid double counting, this was not taken into account in the total. HNSR\&pothetical nonsymbiotic reference scenario; CNSRS- current nonsymbiotic reference scenario; CRSRS=current symbiotic reference scenario; HSRS=hypothetical symbiotic reference scenario.

TA B L E 5 Number of reference scenarios according to the types of studied scenario

\begin{tabular}{|c|c|c|c|c|c|c|c|c|}
\hline & & \multicolumn{6}{|c|}{ Number of reference scenarios } & \multirow[b]{2}{*}{ Total } \\
\hline & & $\overline{0}$ & $\mathbf{I}$ & 2 & 3 & 4 & 5 & \\
\hline \multirow[t]{3}{*}{ Type of studied scenario } & Prospective symbiosis & 0 & 8 & 1 & 0 & 1 & 1 & 11 \\
\hline & Optimized symbiosis & 0 & 3 & 0 & 0 & 0 & 0 & 3 \\
\hline & Total & 1 & 18 & 4 & 1 & 1 & 1 & 26 \\
\hline
\end{tabular}

\subsection{Cross-analysis between the type of reference scenario and the type of functional unit}

The functional unit is the key point to allow the comparison of different scenarios in LCA. It represents the quantified performance (the function) of the compared scenarios. In IS case studies, the studied scenario and the reference scenarios are built to satisfy the defined functional unit. This functional unit should take into account the complexity of industrial symbioses that include several companies with different functions.

Table 4 shows that 20 out of the 26 authors choose to fix their functional unit according to the outputs of the system, whereas five out of the 26 authors choose to fix their functional unit to an input flow. For HNSRS, the use of the functional unit was based on the output (10 out of 11 ), whereas one of the papers fixed it according to the inputs. For CNSRS, the preferentially used functional unit was based on the outputs (seven out of 11), whereas functional units based on an input flow were in the minority (four out of 11). For CSRS and HSRS, the functional unit was based on the output.

A one-dimensional functional unit was used in almost every type of reference scenario and in the majority of CNSRS (10 out of 11), while it was in the minority for HNSRS (four out of 11) and not encountered for CSRS or HSRS. The use of multidimensional functional unit (e.g., the total production of the whole system, or the production of the main products of the system) was mainly encountered for HNSRS (seven out of 11), while it was used by a minority for CNSRS (one out of 11). For CSRS, a multidimensional functional unit was also used. Surprisingly, one paper uses no reference scenario (Zhang et al., 2017). This paper will not be considered in the count for Tables 4-8.

To attempt the description of the complexity level of the studied systems, the count of reference flows for each multidimensional functional unit could be very useful. However, it was very difficult to estimate the number of reference flows due to the read of the papers. Indeed, the number of reference flows is obviously very high for all case studies with a multidimensional functional unit except one with only three reference flows. 
TA B L E 6 Number of reference scenarios according to the types of reference scenarios

\begin{tabular}{|c|c|c|c|c|c|c|c|}
\hline & & \multicolumn{5}{|c|}{ Number of reference scenarios } & \multirow[b]{2}{*}{ Total } \\
\hline & & $\overline{\mathbf{I}}$ & 2 & 3 & 4 & 5 & \\
\hline \multirow[t]{3}{*}{ Type of reference scenarios } & HNSRS & 7 & 3 & 0 & 0 & 0 & 10 \\
\hline & CSRS & 3 & 0 & 0 & 0 & 0 & 3 \\
\hline & HNSRS and HSRS & 0 & 0 & 1 & 0 & 0 & 1 \\
\hline
\end{tabular}

HNSRS= hypothetical nonsymbiotic reference scenario; CNSRS=current nonsymbiotic reference scenario; CRSRS= current symbiotic reference scenario; HSRS= hypothetical symbiotic reference scenario.

TA B L E 7 Use of sensitivity analysis in the reference scenario according to the types of reference scenarios

\begin{tabular}{|c|c|c|c|c|}
\hline & & \multicolumn{3}{|c|}{ Use of sensitivity analysis } \\
\hline & & $\overline{\text { Yes }}$ & $\overline{\text { No }}$ & Total \\
\hline \multirow[t]{3}{*}{ Type of reference scenario } & HNSRS & 3 & 7 & 10 \\
\hline & CSRS & 0 & 3 & 3 \\
\hline & HNSRS and HSRS & 1 & 0 & 1 \\
\hline
\end{tabular}

HNSRS= hypothetical nonsymbiotic reference scenario; CNSRS=current nonsymbiotic reference scenario; CRSRS= current symbiotic reference scenario; HSRS $=$ hypothetical symbiotic reference scenario.

TA B L E 8 Type of data according to the types of reference scenarios

\begin{tabular}{|c|c|c|c|c|c|}
\hline & & \multicolumn{3}{|c|}{ Type of data used for reference scenarios } & \multirow[b]{2}{*}{ Total } \\
\hline & & Site-specific & Average & Site-specififf average & \\
\hline \multirow[t]{3}{*}{ Type of reference scenario } & HNSRS & 0 & 8 & 2 & 10 \\
\hline & CSRS & 1 & 0 & 2 & 3 \\
\hline & HNSRS and HSRS & 0 & 0 & 1 & 1 \\
\hline
\end{tabular}

HNSRS= hypothetical nonsymbiotic reference scenario; CNSRS=current nonsymbiotic reference scenario; CRSRS= current symbiotic reference scenario; HSRS= hypothetical symbiotic reference scenario.

\subsection{Cross-analysis between the number of reference scenarios and the type of studied scenario and th reference scenario}

For each case study, and hence for each type of studied scenario, at least one reference scenario was designed. The following cross-analysis aimed to identify potential correlations between the types of studied scenario and number of reference scenarios used considering the variability of reference scenarios (Table 5).

The large choice of alternatives scenarios based on the studied scenario can lead LCA practitioners to multiply reference scenarios. As we have seen, authors can choose to design different types of reference scenarios to compare them with the studied scenarios, for example, an equivalent nonsymbiotic reference scenario and a symbiotic reference scenario at the same time. But they can also choose to multiply the reference scenarios according to a single type of reference scenario.

Despite this possibility, the majority of the studied papers (18 out of 26) presented only one reference scenario, whereas seven papers presented at least two reference scenarios. Studies of prospective symbiosis preferentially used one reference scenario (eight out of 11) as well as current symbiosis (seven out of 12). The optimized symbiosis case study also used one reference scenario.

For HNSRS, seven papers used only one reference scenario and three papers used two reference scenarios. For CNSRS,only one reference scenario was used in eight cases out of 11 . For CSRS, only one reference scenario was used. 


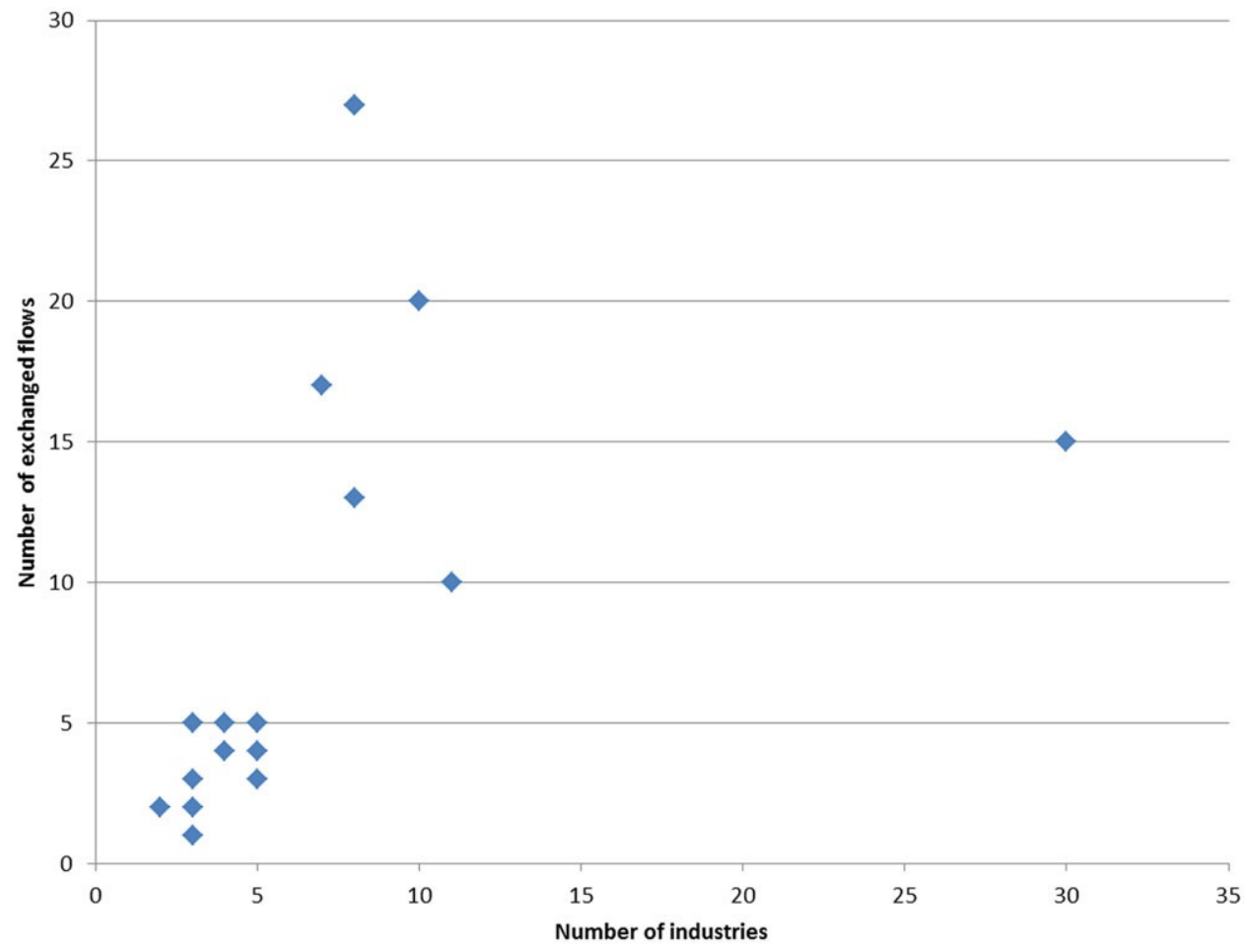

F I G U R E Links between the number of exchanged flows and the number of industries/companies [Color figure can be viewed at wileyonlinelibrary.com]

\section{4 | Cross-analysis between the type of reference scenario and the use of sensitivity analysis}

The aim of sensitivity analysis is to check if the variability of a chosen parameter of a system would modify its environmental results and if this change is significant. The aim of this cross-analysis was to identify correlations between the type of reference scenario and the use of sensitivity analysis (Table 7).

Sensitivity analysis is often conducted after the reference scenario design and the first LCA results are produced. The majority of the papers (18) in the corpus did not perform (or did not mention) the use of sensitivity analysis and only seven papers used one. For HNSRS, only three out of the 10 papers concerned performed a sensitivity analysis, and for CNSRS, only three out of the 11 papers concerned performed a sensitivity analysis; no papers used the single CSRS, whereas the only case study with HSRS did conduct a sensitivity analysis. We observed that case studies with at least two reference scenarios conducted a sensitivity analysis in six cases out of seven.

\section{5 | Cross-analysis between the number of industries/companies and the number of exchanged flows}

To understand how the symbiosis level influences the design of reference scenarios, an analysis of the link between the number of industries/companies/stakeholders and the number of exchanged flows was performed. This analysis was quite difficult and incomplete because of lack of this type of information in the studied papers. Among these 26 papers, most of them (17) present less than 10 exchanged flows (nine papers with less than five flows). Six papers show the exchange of more than 10 flows but less than 20 and only two papers present more than 20 exchanged flows (it is the same IS for both papers). An analysis of the link between the number of industries/companies and the number of exchanged flows was performed without the consideration of papers focusing on a particular symbiosis such as urban symbiosis (Figure 2).

Indeed for urban symbiosis (six papers in the corpus), it is very difficult to evaluate the number of concerned industries or stakeholders. For classical IS described in the corpus, we can observe that for a number of industries less than five, the number of exchanged flows do not exceed 10. For a number of industries more than 10 , the number of exchanged flows varies and exceeds 10 . It obviously appears that the symbiosis level represented by the number of industries involved and the number of exchanged flows constraints the design of reference scenario that explains its variability issue. Indeed for the three papers with more than 20 exchanged flows, a sensitivity analysis was performed.

\subsection{Cross-analysis between the type of reference scenario and the type of data}

The type of data used to design the reference scenarios can reveal the study context and the robustness and the relevance of the inventory and hence, the robustness of the comparison with the studied scenario. That is why we conducted a cross-analysis between the type of data and the 
type of reference scenario (Table 8). Two types of data were found in this corpus:

- Site-specific data that imply in-depth knowledge of the operating of the reference scenario and on-site data collection.

- Average data that imply the desire to model the reference scenario very realistically even if data collection is impossible. These data come from statistics, database, reports, or from the literature, and were collected at different scales (regional, national, or global).

LCA practitioners mainly chose average data (eight out of 10) to produce the inventory of the HNSRS. Seven papers used both types of data but it is a minority of papers according to an analysis based on the type of reference scenario. For CNSRS and CSRS, the authors used, respectively, specific data (five out of 11 and one out of three) or average data (four out of 11 and two out of three). However, the CSRS was designed with site-specific data like the HNSRS and the HSRS.

\subsection{Consideration of territorial aspects}

The territorial aspects were included in the critical review analysis when the definition and the design of the scenario reference accounted for the local context, for example, the best available local technologies, the regional management of waste and by-products, prevailing policy and also the decision process of local agents. Economic and social aspects were also assessed to quantify the economic benefits and the number of jobs created by IS. What is the decision process toward the more relevant scenario according to the local context and sustainability conditions? Only two case studies identified the territorial aspects to define and design their reference scenario (Table 3). Eckelman and Chertow (2013) took into account the economic issues of the waste management in Honolulu to build their HNSRS. These considerations led to a search for alternative processes to manage the by-products of the system for HNSRS. Geng, Tsuyoshi,and Chen (2010) considered different hypothetical policy options for the management of municipal solid waste leading to different nonsymbiotic scenarios and to a single HNSRS. To sum up, the territorial aspects were rarely taken into consideration in the methodology to design reference scenario. Few authors went further than using site-specific or marginal data by considering policies and economic specificities to build the reference scenario. What is more, the local characteristics were often described as a possible way to implement IS. For example, a proposal by Ammenberg et al. (2015) is to compare the geographic scale for different types of improvement measures to judge the relevance of IS. Ardente, Cellura, Lo Brano, and Mistretta (2009) discuss the advantages of optimizing interrelations and knowledge sharing between local stakeholders. Finally, Martin (2015) questions how the distribution of social and economic benefits could be shared between the companies of IS.

\section{Discussion}

The corpus is mainly composed of case studies concerning current and prospective symbioses. Thus, some conclusions for these two types of symbiosis were drawn on one key issue for the design of reference scenario(s): the problem of variability.

For current and prospective symbiosis scenarios, two clear trends were apparent. To assess the environmental performance of current symbiosis scenarios and prospective symbiosis scenarios, LCA practitioners logically used an HNSRS and a CNSRS, respectively. The HNSRS is a fictitious scenario that can be modeled with only average or marginal data unlike the CNSRS, which is a real situation that has to be modeled with site-specific or average data. Concerning the functional unit, the results of cross-analyses are more contrasting. For both types of reference scenarios, the functional unit was the main type of output (based on the output function or product). However, this was mainly due to the object under study (as mentioned above, LCA of products uses outputs, whereas LCA of waste uses inputs). For the mono- or multifunctionality issue, the trends are opposite between the two types of reference scenario. The functional unit was multidimensional for the comparison between HNSRS and current symbiosis scenario because the heart of the study is a current symbiosis that by definition presents several functions. The functional unit is one-dimensional for the comparison between CNSRS and prospective symbiosis scenario because, even if the heart of the study is a symbiosis, the symbiosis is envisaged in a prospective approach to perhaps improve the environmental performances of the current situation (CNSRS). In this case, LCA practitioners chose to build a functional unit based on the function of the current situation, which was often a single function. Due to cross-analyses, one component of choice emerged: the type of studied scenario. The choice of the type of functional unit and the type of data ensues from the type of studied scenario and the type of reference scenario.

Even though these results could have been expected, two cross-analyses revealed the problem of the variability of reference scenarios: the number of reference scenarios and the use of sensitivity analysis. These two possibilities to tackle the variability issue represented a minority in the corpus but did exist. One third of the papers performed a sensitivity analysis and one third also designed at least two reference scenarios. The aim of showing reference scenario variability is to demonstrate the variability of LCA results and hence the variability of environmental performance of the studied IS as shown by Sokka (2011) and Martin et al. (2015). Authors pointed to the uncertain robustness of LCA conclusions, thereby satisfying the transparency constraint of LCA methodology (ISO, 2006a). The maximum variability of reference scenarios is a major point for the quantification of environmental benefits of IS that can theoretically be compared with all nonsymbiotic alternatives. Although considering 
numerous reference scenarios in LCA may be time consuming, a sensitivity analysis is often preferred over the reference scenario multiplication. The weak point of the sensitivity analyses performed is that they are often limited to a single parameter (modification of an input or an output or technical parameters or type of allocation). It is difficult to estimate the relevant or even the minimum number of parameters for sensitivity analysis because it depends on the nature and the complexity of each LCA case study. The truth is certainly elsewhere, perhaps in a more methodological approach to overcome the variability. A proposal of Sokka (2011) based on Salmi (2007) focuses on the use of a counterfactual method to define and design reference scenarios. The counterfactual method aims at giving answers to the question "what might have been?" (Roese \& Olson, 1995). This method is particularly relevant to define reference scenarios for LCA of current IS because LCA practitioners have to answer the following question: what if the current symbiosis had not taken place? We can imagine the same approach for LCA of prospective IS in order to create different future reference scenarios based on the current nonsymbiotic situation. For both studied scenarios (current IS and prospective IS), the definition and the design of a minimum of two reference scenario due to a counterfactual method is a possible fallback solution to reveal the environmental performance variability (European Commission, 2010). These two reference scenarios could represent a worst case and best case.

This proposal does not aim to achieve an exhaustive view of the potential environmental benefits of the studied IS but to determine strict environmental benefits and impacts of IS compared to the worst- and best-case reference scenarios. The question that then arises is how to design these worst- and best-case scenarios and if a standard procedure is needed. Considering territorial aspects is clearly part of the answer (Eckelman \& Chertow, 2013; Martin, 2015). An IS takes place at a regional scale with some social, economic, and environmental specificities. The IS presents some interactions with its surroundings and so its design depends on these interactions (Dumoulin, Wassenaar,Avadí, \& Paillat, 2016; Loiseau et al., 2018). Territorial aspects could be of differents types: organizational as regulation issues, technical as by-product outlets or the possible use of local best available technologies, social as the point of view, perceptions, needs, and constraints of the different stakeholders. To perform a counterfactual approach to define and design the reference scenario, LCA practitioners should integrate territorial aspects. The consideration of such aspects could be based on a work with different stakeholders and on a systemic territorial diagnosis (Loiseau et al., 2018) to understand the stakeholders' perception concerning the territory (Dumoulin et al., 2016; Mazzi, Toniolo, Catto, De Lorenzi, \& Scipioni, 2017; Sharib \& Halog, 2017), its complexity, and the role of IS within and beyond the territory (Mazzi et al., 2017). This points to a challenging research agenda focusing on a new methodology to consider territorial aspects to define the worst- and best-case reference scenarios. Such a standard and shared methodology is useful to ensure the environmental benefits of IS and the need of improvement especially concerning the interactions with the territory.

\section{5 | CONCLUSION}

The IS system is a practical example of industrial ecology philosophy in creating very strong linkages between companies in order to improve the environmental performance of the system as a whole. The material, energy, or information exchanges ideally aim at reducing environmental impacts such as resource consumption or atmospheric, water, and soil pollution. To ensure this environmental improvement, LCA is often used to assess environmental impacts. LCA is based on a comparison between the studied scenario (in this case, the IS) and reference scenarios. A reference scenario is needed as a benchmark for the environmental performance of IS scenario. The quality and relevance of the reference scenario is essential to guarantee the robustness of the environmental assessment.

We conducted a review of 26 peer-reviewed papers focused on LCA of industrial symbioses to identify how LCA practitioners define and design these reference scenarios. Six cross-analyses were conducted checking the correlation between the type of reference scenario, the type of studied IS, and different LCA characteristics. The main and expected conclusion is that the definition of reference scenarios differs according to the studied IS. If the studied scenario is a current IS, the reference scenario is mostly hypothetical and nonsymbiotic. If the studied scenario is a prospective IS, the reference scenario is mostly current and nonsymbiotic.

One problem was revealed by this critical review: the variability of the reference scenario. Some authors tried to resolve this challenge by using sensitivity analysis or by multiplying reference scenarios. Although these methods comply with LCA, they have some limits-particularly, the time required for the multiplication of the number and the combination of parameters tested for the sensitivity analysis. Furthermore, very few authors defined and designed the reference scenario using territorial aspects, constraints, and needs as product outlets, regulation issues, and stakeholder wishes. This is very surprising because of the territorial influence of IS systems, especially for certain type of streams that depend on local supply or outlets: raw material as wood pellet or energy as heat.

One methodological way to address the problem of variability of the reference scenario could be based on the definition and the design of reference scenarios due to a counterfactual method taking into account territorial aspects with the cooperation of stakeholders. This counterfactual method could be based on a territorial diagnosis and a brainstorming with stakeholders and should be easy to use by LCA practitioners who wish to spend more time modeling the industrial scenario rather than the reference scenario. For that, it is advisable to focus the effort on the definition and design of only two territorial reference scenarios, that is, the best- and worst-case scenarios. This is a challenging agenda due to the complexity to manage a territorial diagnosis combined with the perception of stakeholders. To succeed such a counterfactual approach, LCA practitioners need to rely on standard and shared recommendations or procedures that depend as little as possible on the characteristics of IS case studies to ensure the production of LCA results at this objectively. 


\section{ORCID}

Lynda Aissani (iD https://orcid.org/0000-0002-0736-2691

Jean-Baptiste Bahers (iD https://orcid.org/0000-0003-2942-6083

\section{REFERENCES}

Ammenberg, J., Baas, L., Eklund, M., Feiz, R., Helgstrand, A., \& Marshall, R. (2015). Improving the $\mathrm{CO}_{2}$ performance of cement, part III: The relevance of industrial symbiosis and how to measure its impact. Journal of Cleaner Production, 98, 145-155.

Ardente, F., Cellura, M., Lo Brano, V., \& Mistretta, M. (2009). Life cycle assessment-driven selection of industrial ecology strategies. Integrated Environmental Assessment and Management, 6(1), 52-60.

Blengini, G. A., Busto, M., Fantoni, M., \& Fino, D. (2012). Eco-efficient waste glass recycling: Integrated waste management and green product development through LCA. Waste Management, 32, 1000-1008.

Boix, M., Montastruc, L., Azzaro-Pantel, C., \& Domenech, S. (2015). Optimization methods applied to the design of eco-industrial parks: A literature review. Journal of Cleaner Production, 87, 303-317.

Chapman, J. L., \& Reiss, M. J. (1998). Ecology: Principles and applications. Cambridge, England: Cambridge University Press.

Chertow, M. R. (2000). Industrial symbiosis: Literature and taxonomy. Annual Review of Energy and the Environment, 25, 313-337.

Chertow, M. R., \& Lombardi, D. R. (2005). Quantifying economic and environmental benefits of co-located firms. Environmental Science and Technology, 39(17), 6535-6541.

Cohen-Rosenthal, E. (2004). Making sense out of industrial ecology: A framework for analysis and action. Journal of Cleaner Production, 12, 1111-1123.

Côté, R. P., \& Cohen-Rosenthal, E. (1998). Designing eco-industrial parks: A synthesis of some experiences. Journal of Cleaner Production, 6(3-4), 181-188.

Daddi, T., Nucci, B., \& Iraldo, F. (2017). Using life cycle assessment (LCA) to measure the environmental benefits of industrial symbiosis in an industrial cluster of SMEs. Journal of Cleaner Production, 147, 157-164.

Dong, H., Ohnishi, S., Fujita, T., Geng, Y., Fujii, M., \& Dong, L. (2014). Achieving carbon emission reduction through industrial \& urban symbiosis: A case study of Kawasaki. Energy, 64, 277-286.

Dumoulin, F., Wassenaar, T., Avadí, A., \& Paillat, J. M. (2016). A framework for accurately informing facilitated regional industrial symbioses on environmental consequences. Journal of Industrial Ecology, 21, 1049-1067.

Eckelman, M., \& Chertow, M. (2013). Life cycle energy and environmental benefits of a US industrial symbiosis. International Journal of Life Cycle Assessment, 18(8), 1524-1532.

Ehrenfeld, J., \& Gertler, N. (1997). Industrial ecology in practice: The evolution of interdependence at Kalundborg. Journal of Industrial Ecology, 1(1), 67-79.

European Commission. (2010). International reference life cycle data system (ILCD) handbook. General guide for life cycle assessment-Detailed guidance (1st ed.). EUR 24708 EN. Luxembourg: Author.

Ferrão, P., Lorena, A., \& Ribeiro, P. (2016). Industrial ecology and Portugal's national waste plans. In R. Clift \& A. Druckman (Eds.), Taking stock of industrial ecology (pp. 275-289). Berlin: Springer.

Geng, Y., Tsuyoshi, F., \& Chen, X. (2010). Evaluation of innovative municipal solid waste management through urban symbiosis: A case study of Kawasaki. Journal of Cleaner Production, 18, 993-1000.

Gerber, L., Fazlollahi, S., \& Maréchal, F. (2013). A systematic methodology for the environomic design and synthesis of energy systems combining process integration, life cycle assessment and industrial ecology.Computers and Chemical Engineering, 59, 2-16.

Hashimoto, S., Fujita, T., Geng, Y., \& Nagasawa, E. (2010). Realizing @®ission reduction through industrial symbiosis: A cement production case study for Kawasaki. Resources, Conservation and Recycling, 54(10), 704-710.

International Standard Organization (ISO). (2006a). Environment management-Life cycle assessment_-Principles and framework. Switzerland: Author.

International Standard Organization (ISO). (2006b). Environmental management_Life cycle assessment—Requirements and guidelines. Switzerland: Author.

Jacobsen, N. B. (2006). Industrial symbiosis in Kalundborg, Denmark: A quantitative assessment of economic and environmental aspects. Journal of Industrial Ecology, 10(1-2), 239-255.

Jensen,P.D., Bassona, L., Hellawell, E. E., Bailey, M. R., \& Leacha, M. (2011). Quantifying 'geographic proximity': Experiences from the United Kingdom's national industrial symbiosis programme. Resources, Conservation and Recycling, 55(7), 703-712.

Kastner, C. A., Lau, R., \& Kraft, M. (2015). Quantitative tools for cultivating symbiosis in industrial parks; a literature review. Applied Energy, 155, 599-612.

Lim, S.-R., \& Park, J. M. (2010). Interfactory and intrafactory water network system to remodel a conventional industrial park to a green eco-industrial park. Industrial Engineering Chemical Research, 49(3), 1351-1358.

Liu, Q., Jiang, P., Zhao, B., Bian, H., \& Qian, G. (2011). Life cycle assessment of an industrial symbiosis based on energy recovery from dried sludge and used oil. Journal of Cleaner Production, 19(15), 1700-1708.

Loiseau, E., Aissani, L., Le Féon, S., Laurent, F., Cerceau, J., Sala, S., \& Roux, P. (2018). Territorial life cycle assessment (LCA): What exactly is it about? A proposal towards using a common terminology and a research agenda. Journal of Cleaner Production, 176, 474-485. 
Lowe, E. A., \& Evans, L. K. (1995). Industrial ecology and industrial ecosystems. Journal of Cleaner Production, 3, 47-53.

Martin, M. (2013). Industrial symbiosis in the biofuel industry: Quantification of the environmental performance and identification of synergies (Academic dissertation), Linköping, Sweden.

Martin, M. (2015). Quantifying the environmental performance of an industrial symbiosis network biofuel producers. Journal of Cleaner Production, 102, 202-212.

Martin, M., Svensson,N., \& Eklund, M. (2015). Who gets the benefits? An approach for assessing the environmental performance of industrial symbiosis. Journal of Cleaner Production, 98, 263-271.

Martin, M., Svensson,N., Fonseca,J., \& Eklund, M. (2014). Quantifying the environmental performance of integrated bioethanol and biogas production. Renewable Energy, 61, 109-116.

Mattila, T., Lehtoranta, S., Sokka, L., Melanen, M., \& Nissinen, A. (2012). Methodological aspects of applying life cycle assessment to industrial symbioses. Journal of Industrial Ecology, 16(1), 51-60.

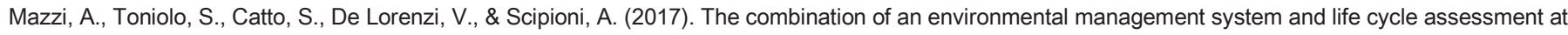
the territorial level. Environmental Impact Assessment Review, 63, 59-71.

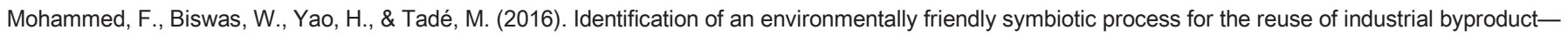
An LCA perspective. Journal of Cleaner Production, 112(4), 3376-3387.

Roese, N. J., \& Olson, J. M. (1995). What might have been-The social psychology of counterfactual thinking. Mahwah, NJ: Laurence Erlbaum.


chemical companies. Journal of Cleaner Production, 86, 125-131.

Salmi, O. (2007). Eco-efficiency and industrial symbiosis-A counterfactual analysis of a mining community. Journal of Cleaner Production, 15, 1696-1705.

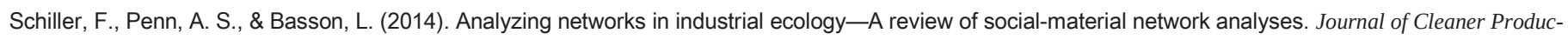
tion, 76, 1-11.

Sharib, S., \& Halog, A. (2017). Enhancing value chains by applying industrial symbiosis concept to the Rubber City in Kedah, Malaysia. Journal of Cleaner Production, 141, 1095-1108.

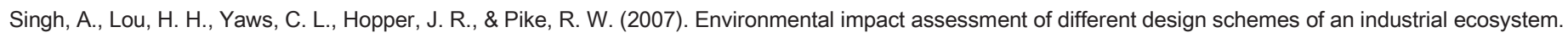
Resources, Conservation and Recycling, 51(2), 294-313.

Sokka, L. (2011). Local systems, global impacts: Using life cycle assessment to analyse the potential and constraints of industrial symbioses (Academic dissertation), University of Helsinki, Finland.

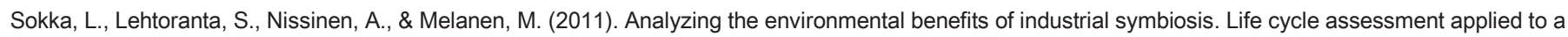
Finnish forest industry complex. Journal of Industrial Ecology, 15(1), 137-155.

Sokka, L., Pakarinen, S., \& Melanen, M. (2011). Industrial symbiosis contributing to more sustainable energy use - an example from the forest industry in Kymenlaakso, Finland. Journal of Cleaner Production, 19(4), 285-293.

Soratana, K., \& Landis, A. (2011). Evaluating industrial symbiosis and algae cultivation from a life cycle perspective. Bioresource Technology, 102(13), 6892-6901.

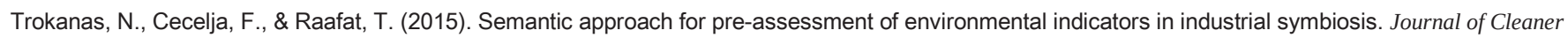
Production, 96, 349-361.

Van Berkel, R. (2010). Quantifying sustainability benefits of industrial symbioses. Journal of Industrial Ecology, 14(3), 371-373.

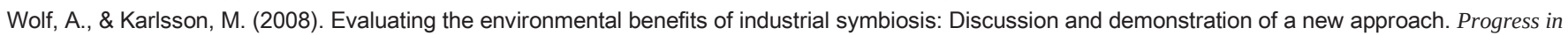
Industrial Ecology-An International Journal, 5(5-6), 502-517.

Yu,F.,Han, F.,\& Cui, Z. (2015). Assessment of life cycle environmental benefits of an industrial symbiosis cluster in China. Environmental Science Pollution Research, 22(7), 5511-5518.

\section{SUPPORTING INFORMATION}

Additional supporting information may be found online in the Supporting Information section at the end of the article.

How to cite this articlespisani L, Lacassagne ABahers J-B, Féon SL.Life cycle assessment of industrial symbiosis: A critical review of relevant reference scenarios. J Ind Ecol. 2019;1-14. https://doi.org/10.1111/jiec.12842 